\title{
Side-Specificity of Olfactory Learning in the Honeybee: US Input Side
}

\author{
Jean-Christophe Sandoz, ${ }^{2,3}$ Martin Hammer, ${ }^{1}$ and Randolf Menzel
}

Freie Universität Berlin, Institut für Biologie-Neurobiologie, 14195 Berlin, Germany

\begin{abstract}
In honeybees, Apis mellifera L., the proboscis extension reflex (PER) can be conditioned by associating an odor stimulus (CS) with a sucrose reward (US). As the neural structures involved in the detection and integration of CS and US are bilaterally symmetrical in the bee brain, we ask what respective role each brain side plays in the conditioning process. More specifically, the US normally used in conditioning experiments is the compound stimulation of the antennae (which triggers the PER) and of the proboscis (where bees lick the sucrose solution). Anatomically, the brain receives unilateral US input through each antenna, but bilateral input from the proboscis. By controlling each US component, we show that an antenna-US produces unilateral sensitization, whereas a proboscis-US or a compound-US induces bilateral sensitization. Bees can learn a unilateral odor CS with all three USs, but when a proboscis-US is used, new learning is inhibited on the contralateral side, owing to a possible US-preexposure effect. Furthermore, we show that the antenna-US induces both unilateral and bilateral reinforcement processes, whereas the proboscis-US produces only bilateral effects. Based on these data, we propose a functional model of the role of each brain side in processing lateralized CSs and USs in olfactory learning in honeybees.
\end{abstract}

Associative learning requires the anatomical and functional convergence of the signal to be learned with the reinforcing signal. If the input sides of the two signals are lateralized, one might ask whether the associative connections are established independently on both sides or whether sufficient cross-talk exists between the two sides of the nervous system to lead to a memory trace independent of the respective input side. In particular cases, for example, visual imprinting and aversive learning in the chick, access to the formation and retrieval of the memory trace might be limited to only one input side, although the sensory systems are bilaterally symmetrical (Sandi et al. 1993; Horn 1998; Rose 2000). In such a case, the memory exists or is accessible only in one side of the brain (Vallortigara 2000). Side-specificity of cognitive functions in the human brain is also indicative of asymmetrical representations of the respective memory traces (Springer and Deutsch 1981), and, again, the memory can be established and retrieved only via the appropriate lateralized sensory input.

In honeybees, Apis mellifera L., evidence exists for both side-specific and bilateral learning phenomena. Concerning the CS in both free-flying and harnessed bees, it was found that the olfactory input side is strongly connected to the respective odor, forming a spatial-olfactory compound as a learning signal (Masuhr and Menzel 1972; Sandoz and

${ }^{1}$ Deceased.

${ }^{2}$ Present address: Ethologie et Cognition Animale, Université Paul Sabatier, 118, Route de Narbonne, 31062 Toulouse cedex 04, France.

${ }^{3}$ Corresponding author.

E-MAIL sandoz@cict.fr; FAX +33561556154.

Article and publication are at http://www.learnmem.org/cgi/doi/ $10.1101 / \mathrm{lm} .50502$.
Menzel 2001). Bees can thus learn side-specific olfactory information. However, a unilaterally learned association was found to also be retrievable from the other brain side after a retention period (Sandoz and Menzel 2001). Moreover, interfering with the early process of memory consolidation after a single unilateral olfactory conditioning trial by local cooling revealed that only the ipsilateral antennal lobe, the primary olfactory neuropil, contributes to memory formation, but that both sides of the mushroom bodies, the second-order olfactory and higher-order multisensory integration center, are involved in memory formation (Menzel et al. 1974; Erber et al. 1980). These observations are interpreted as indicating a distributed memory trace across the midline of the higher-order neuropils, even after unilateral conditioning. Other studies indicate that both brain sides are needed for solving particular learning tasks. For instance, Thorn and Smith (1997) suggested that reduced learning of odor component $\mathrm{A}$ in a mixture of two odorants (AB) after learning B (the phenomenon of "blocking") requires CS input on both sides (for a detailed discussion on the existence of the blocking phenomenon in bees, see Gerber and Ullrich 1999; Hosler and Smith 2000). Consistently, we found recently (B. Komischke, J.C. Sandoz, H. Lachnit, and M. Giurfa, in prep.) that bees can solve the nonelemental discrimination task $\mathrm{A}+\mathrm{B}+\mathrm{AB}-$ (negative patterning discrimination) only with olfactory input from both sides. Therefore, associative olfactory learning in the honeybee relies both on unilateral and bilateral CS processes. As for the US, until now very little work has sought to understand the influence of the US input site on learning.

The US normally provided in conditioning experiments with honeybees (and present in natural foraging situations)

LEARNING \& MEMORY 9:337-348 @ 2002 by Cold Spring Harbor Laboratory Press ISSN1072-0502/02 \$5.00

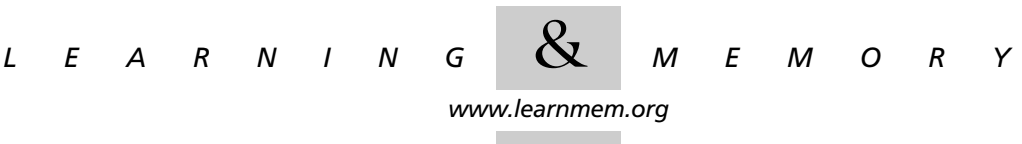


is a compound of sucrose stimulation, first at the level of the antenna (which triggers the proboscis extension reflex), and then at the proboscis (the bee then licks some of the sucrose solution). Bitterman et al. (1983) already indicated that each US component alone can act as a reinforcer. However, the influence of each US component on the side-specificity of olfactory learning is utterly unknown. One can hypothesize that the antenna-US involves either a unilateral stimulation (when given to one antenna) or a bilateral stimulation (when given to both antennae) and that the proboscis-US provides a bilateral stimulation. How are these either unilateral or bilateral US components processed, and what is their respective role in the establishment of associative memory traces? We addressed these questions by using a series of behavioral procedures in which we controlled and varied the site of US input. In addition, we compared the ability of bees to be conditioned with an antenna-US or a proboscis-US alone, as compared with the usual compound-US.

\section{RESULTS}

A general overview of the experimental protocols is provided in Table 1. On each experimental day, identical numbers of bees received a given set of stimulations on the left as on the right side.

\section{Experiment 1: Effect of US Input Site on Sensitization}

In this experiment, we evaluated the influence of the different US components on sensitization. In particular, we asked whether the antennal components of the US produce unilateral or bilateral sensitization.

\section{Protocol}

Between 24 and 12 min before the sensitization procedure began, bees were subjected to one pretest with clove oil odor (see Materials and Methods) on each side. Bees that responded spontaneously to the odor on either side were discarded $(17.6 \%$, $n=142$ ). Three groups of animals were sensitized with (1) an antenna-US, (2) a proboscis-US, or (3) a compound-US, respectively. Bees were then tested twice with the clove oil odor on one side, first after $30 \mathrm{sec}$ and again after $12 \mathrm{~min}$. According to previous studies (Menzel et al. 1991; Hammer et al. 1994), the highest responsiveness to the odor is expected after $30 \mathrm{sec}$ (sensitization), whereas after $12 \mathrm{~min}$, sensitization effects should have disappeared. In cases 1 and 3, responses were compared between the side ipsilateral to the US stimulation (one subgroup) and the contralateral side (second subgroup). In case 2 , where no lateral US was given, the responses were compared between the left (one subgroup) and right (second subgroup) sides.

\section{Results}

Figure 1 presents the percentages of responses to the clove oil odor, $30 \mathrm{sec}$ or $12 \mathrm{~min}$ after a sensitizing stimulus was applied as an antenna-US, a proboscis-US, or a compoundUS. Thirty seconds after the US, sensitization responses to clove oil were high, between $26 \%$ and $45 \%$ in all groups, except in one case: bees that received an antenna-US showed sensitization only when the odor was ipsilateral to the US (36\%) and not when presented on the contralateral side (6\%). This difference was significant $(G=5.3, P<0.05$, 1 df). No statistical differences appeared between sides for groups sensitized using a proboscis-US or a compound-US. After $12 \mathrm{~min}$, responses in all groups were $<15 \%$, showing that the effect of sensitization had by then disappeared. Thus, an antenna-US provides unilateral sensitization, restricted to the side of US application, whereas proboscis-US and compound-US induce bilateral sensitization.
Table 1. Experiment Protocols: Schematic Design of the Experiments, Detailing the CS and US Presentations Performed in Each Experimental Group

\begin{tabular}{|c|c|c|c|c|c|}
\hline \multirow[b]{2}{*}{ Experiment } & \multirow[b]{2}{*}{ Groups } & \multicolumn{2}{|c|}{ Phase 1} & \multicolumn{2}{|c|}{ Phase 2} \\
\hline & & CS & US & CS & US \\
\hline 1 & $\begin{array}{l}\text { Antenna-US } \\
\text { Proboscis-US } \\
\text { Compound-US }\end{array}$ & - & $\begin{array}{l}\mathrm{A}_{1} \\
\mathrm{P} \\
\mathrm{A}_{1}+\mathrm{P}\end{array}$ & $A_{1}$ or $A_{2}$ & - \\
\hline 2 & $\begin{array}{l}\text { Antenna-US } \\
\text { Proboscis-US } \\
\text { Compound-US }\end{array}$ & $A_{1}$ & $\begin{array}{l}\mathrm{A}_{1} \\
\mathrm{P} \\
\mathrm{A}_{1}+\mathrm{P}\end{array}$ & $\mathrm{A}_{2}$ & $\begin{array}{l}\mathrm{A}_{2} \\
\mathrm{P} \\
\mathrm{A}_{2}+\mathrm{P}\end{array}$ \\
\hline 3 & $\begin{array}{l}\text { Placement } \\
\text { Proboscis-US only } \\
\text { CS-proboscis-US }\end{array}$ & $\overline{-}$ & $\begin{array}{l}- \\
P \\
P\end{array}$ & $\mathrm{~A}_{2}$ & $\mathrm{P}$ \\
\hline $4^{*}$ & $\begin{array}{l}\text { US same side } \\
\text { CS cut side }\end{array}$ & $\begin{array}{l}\mathrm{A}_{1} \\
\mathrm{~A}_{2} \text { (cut) }\end{array}$ & $\begin{array}{l}A_{1} \\
A_{1}\end{array}$ & - & - \\
\hline 5 & $\begin{array}{l}\text { US both side } \\
\text { US same side } \\
\text { US opposite side }\end{array}$ & $\mathrm{A}_{1}$ & $\begin{array}{l}A_{1}+A_{2} \\
A_{1} \\
A_{2}\end{array}$ & $\mathrm{~A}_{2}$ & $\begin{array}{l}\mathrm{A}_{1}+\mathrm{A}_{2} \\
\mathrm{~A}_{2} \\
\mathrm{~A}_{1}\end{array}$ \\
\hline $6^{*}$ & $\begin{array}{l}\text { US both side } \\
\text { US same side } \\
\text { US opposite side }\end{array}$ & $\mathrm{A}_{1}$ & $\begin{array}{l}\mathrm{A}_{1}+\mathrm{A}_{2} \\
\mathrm{~A}_{1} \\
\mathrm{~A}_{2}\end{array}$ & - & - \\
\hline
\end{tabular}

For half the bees, side 1 was the right side, and for the other half, it was the left side (vice versa for side 2). The CS was either given to the side-1 antenna $\left(A_{1}\right)$ or to the opposite (side 2 ) antenna $\left(A_{2}\right)$. The US was given to one or two antennae $\left(A_{1}, A_{2}\right.$, or $\left.A_{1+2}\right)$, to the proboscis $(P)$ or to both an antenna and the proboscis $\left(A_{1}+P\right.$ or $\left.A_{2}+P\right)$. In two experiments (see asterisk), bees were subjected to a differential conditioning procedure. In this case, both CS+ and CS- were presented on the same side, which is indicated in the column.

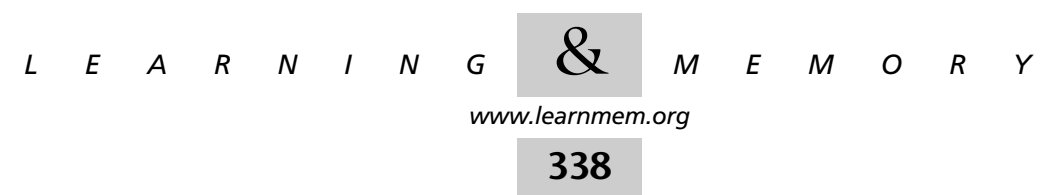




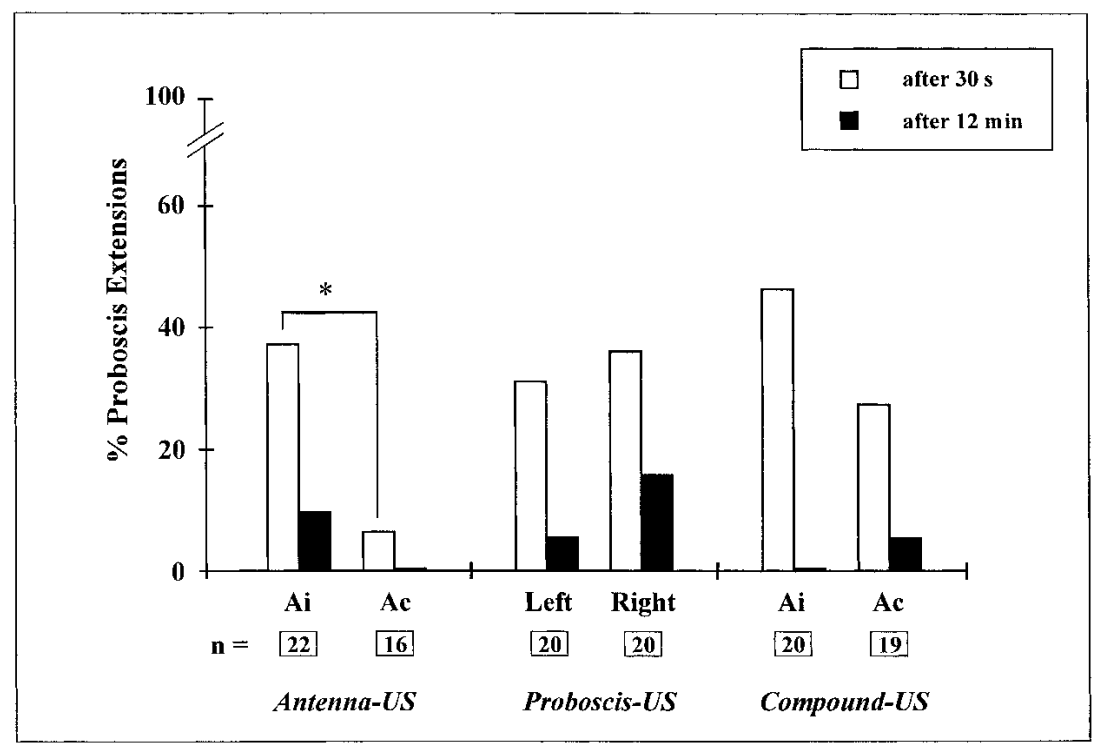

Figure 1 Responses of bees in a sensitization experiment with the different US components: antenna-US, proboscis-US, and compound-US. Sensitization is observed as an increased response to an odor shortly $(30 \mathrm{sec})$ but not later (12 $\mathrm{min})$ after US stimulation. Antenna-US led to unilateral sensitization, whereas proboscis-US and compound-US showed no significant differences between sides. $\left({ }^{*}\right) P<0.05, G$-test.

\section{Experiment 2: Effect of US Input Site on Conditioning}

We investigated the influence of the US input site on conditioning with a unilateral CS. More precisely, we asked whether bees can learn a CS when associated with any US components, and what effect such learning has on the opposite brain side.

\section{Protocol}

The experiment consisted of two acquisition phases of four conditioning trials (9-min intertrial intervals). The CS was directed to one antenna during Phase 1 , and to the opposite antenna during Phase 2. As in Experiment 1, three groups of bees were trained according to the properties of the US: antenna-US, proboscis-US, or compound-US. Antennal components of the US (in the case of antenna-US or compound-US groups) were always presented ipsilaterally to the CS, that is, on one given side in Phase 1 , and on the opposite side in Phase 2.

\section{Results}

During the first phase of the procedure, bees from all three groups showed acquisition of conditioned responses to the unilateral CS, from $8 \%-20 \%$ at the first trial to $42 \%-45 \%$ at the fourth trial (Fig. 2). No significant difference appeared among groups in this phase. When the CS changed sides (trial 5-note that the antennal US also changed sides, but was given after the response in trial 5 was recorded), responses were low on the opposite side (between $11 \%$ and $26 \%$ ). This indicates that in such a procedure with short intertrial intervals, a transfer between sides has not yet occurred, confirming a previous study (Sandoz and Menzel 2001). During the second acquisition phase, performances differed between groups: whereas bees from antenna-US and compound-US groups showed an increase in conditioned responses (from 11-26 to $41 \%-45 \%$ ), performances of the proboscis-US group remained low $(<31 \%)$. This difference was significant (log-linear analysis, partial and marginal association $\chi^{2}>8.0, \quad P<0.05,2$ df). Two-by-two comparisons showed that the compound-US and antenna-US groups performed similarly in the second phase (partial and marginal associations $\chi^{2}<0.6$, NS, $1 \mathrm{df}$ ), but both groups responded significantly more than the proboscis-US group (partial and marginal associations $\chi^{2}>4.08, P<0.05,1$ df). Thus, bees' learning performances were similar with all US components, and when the CS was switched to the opposite side, bees conditioned with a proboscis-US showed a resistance to acquisition as compared with bees conditioned with an antenna-US or a compound-US.

\section{Experiment 3: Associative Dependency of the Proboscis-US Effect}

This experiment was designed to explain the resistance to acquisition obtained for the proboscis-US group in the second phase of Experiment 2: Was the observed effect caused by an associative process, that is, by an influence of the CS-US association on the contralateral brain side? Or was it caused by an effect of the proboscis-US alone on the opposite brain side? In the latter case, we hypothesize that the reinforcing function of the proboscis-US on the side where no $C S$ is given could produce a US-preexposure effect through the development of a context-US association.

\section{Protocol}

The experiment consisted of two experimental phases of four trials (9-min intertrial intervals). The CS was directed to one antenna during Phase 1, and to the opposite antenna during Phase 2. The US was always applied at the level of the proboscis. In Phase 1, bees were subjected to one of three treatments: (1) placement, as a control situation, in which the bee was placed at each trial in the experimental situation but received neither CS nor US; (2) proboscis-USonly presentations; and (3) conditioning trials (CS-proboscis-US presentations). In Phase 2, all bees were subjected to conditioning trials with a proboscis-US. The third group

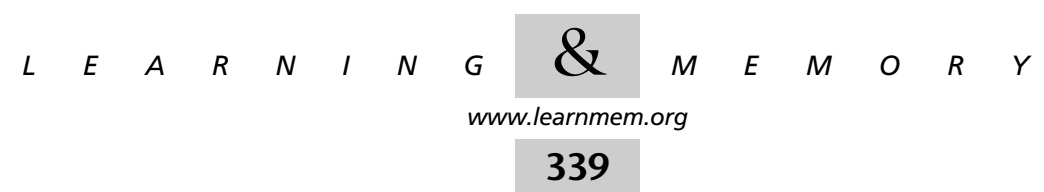




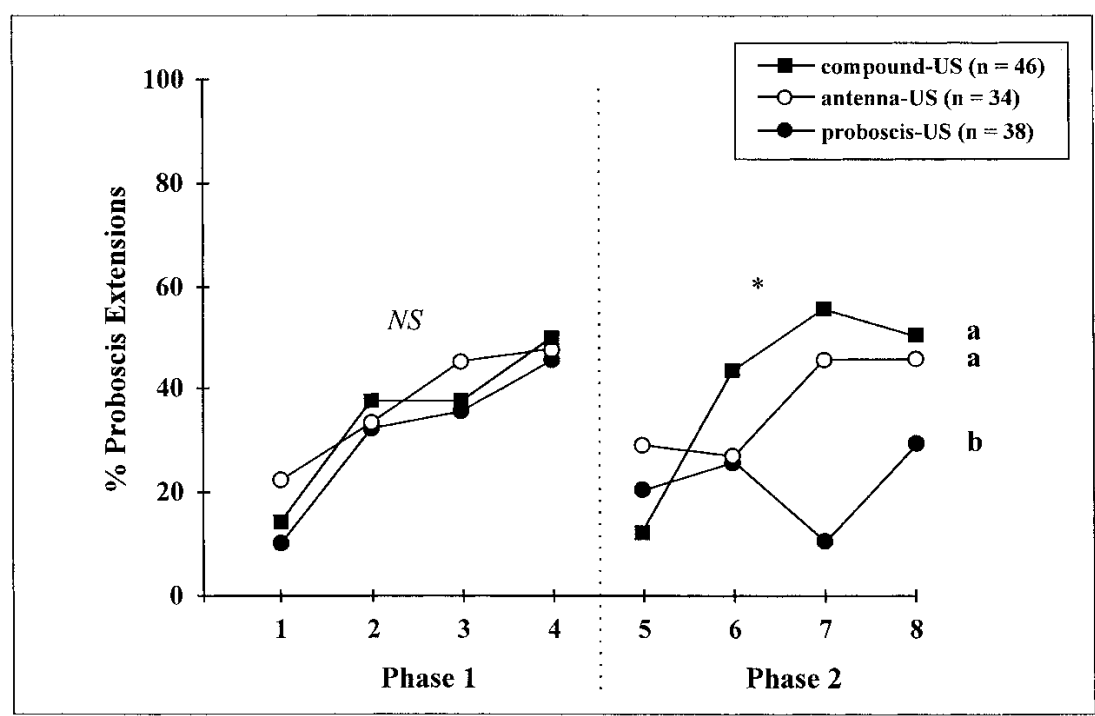

Figure 2 Bees' performances in a conditioning procedure with a unilateral CS and the different US components: antenna-US, proboscis-US, and compound-US. In the first phase, bees from all groups learned the CS-US association. In the second phase, after the CS changed sides, bees receiving a proboscis-US showed a significant blocking of acquisition. (NS) Nonsignificant; $\left({ }^{*}\right) P<0.05, \log$-linear analysis. Different letters indicate significantly different response levels (pairwise log-linear analyses).

was thus equivalent to the proboscis-US group of Experiment 2 .

\section{Results}

Figure 3 presents the acquisition performances of bees in Phase 2. Although performances of the placement group clearly increased during the procedure (from $10 \%$ to $50 \%$ ), those of both the US-proboscis-only group and the conditioning group showed resistance to acquisition (responses from $7 \%-10 \%$ to $27 \%-28 \%$ ). Responses of the different groups of bees were significantly heterogeneous (log-linear analysis, partial and marginal association $\chi^{2}>6.8, P<0.05$, 2 df). Two-by-two comparisons further showed that bees that received only placement trials in the first phase responded significantly more than bees subjected to conditioning trials (partial and marginal association $\chi^{2}>7.0$, $P<0.01,1 \mathrm{df})$. Responses of bees subjected to US-only trials in the first phase of the experiment showed a near-significant difference from those of bees from the placement groups (partial and marginal association $\chi^{2}>3.5, P<0.061$, $1 \mathrm{df})$. These results indicate that the presentation of a proboscis-US, with or without a lateral CS, induces a resistance to the acquisition of this CS on the opposite side.

\section{Experiment 4: CS-Specificity of Antenna- US Conditioning}

We asked whether conditioning with an antenna-US produces an associative memory trace as a compound-US does, that is, a memory trace that is specific to the CS. Critical for such a conclusion is a differential conditioning experiment, where a CS+ is associated to the US, and a CS- is not. If animals significantly differentiate the two CSs (responding to the CS+ but not to the CS-), then performance has an associative basis.

\section{Protocol}

Honeybees were subjected to a differential conditioning procedure, wherein two odors were presented alternately, one being rewarded (CS+) and the other not (CS-). At least $30 \mathrm{~min}$ before conditioning began, one antenna was cut off at the scapus. On each experimental day, half the bees were missing the left antenna and half the right antenna. One group of bees ("US same side") received the two CSs and the US on the intact antenna. A second group ("CS cut side") received the CSs on the side where the antenna was missing, and the US on the intact side. Such a control group allowed us to test the influence of the nonassociative component of the US and the quality of our apparatus: If this group showed responses to the odors during conditioning, it would be either caused by sensitization to the US (in which case, they would respond indifferently to CS+ and CS-), or by odor contaminations from one side of the apparatus to the other (in which case, they would respond more to the CS+ than to the CS-). In both groups, the conditioning procedure consisted of $6 \mathrm{CS}+$ trials and $6 \mathrm{CS}-$ trials, with intertrial intervals of $9 \mathrm{~min}$. On CS+ trials, bees received the CS+ in association with an antenna-US, and on CS- trials, they were stimulated with the CS- odor alone. The procedure began with a CS- trial, and $\mathrm{CS}+(+)$ and $\mathrm{CS}-(-)$ were pseudorandomized in a -++-+--+ order.

\section{Results}

Bees subjected to a differential conditioning procedure with the CSs presented on the cut antenna (Fig. 4, "CS cut side") showed only very few responses throughout the procedure $(<11 \%)$. In contrast, bees conditioned with the CS and the antenna-US on the intact side ("US same side") learned to respond to the CS+ and not to respond to the CS-, showing, respectively, 59\% and $7 \%$ responses at the end of training. The log-linear analysis shows a highly significant difference between groups (partial and marginal association $\chi^{2}>85.2$, $P<0.001,1 \mathrm{df})$. In the "US same side" group, bees responded significantly more to the CS+ than to the CS- (partial and marginal association $\chi^{2}>30.1, P<0.001,1 \mathrm{df}$ ), whereas in the "CS cut side" group they did not (partial and marginal association $\chi^{2}<1.29$, NS, $1 \mathrm{df}$ ). Thus, an antennaUS is capable of producing a specific CS-US association like

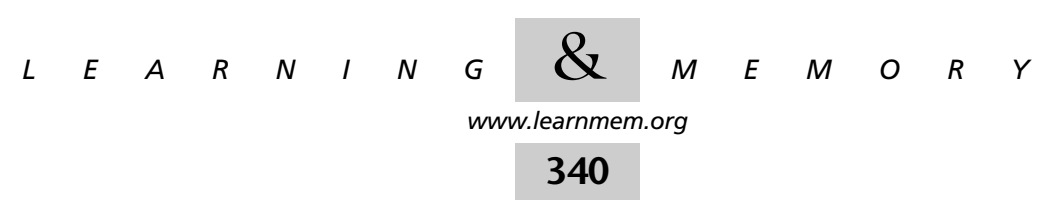




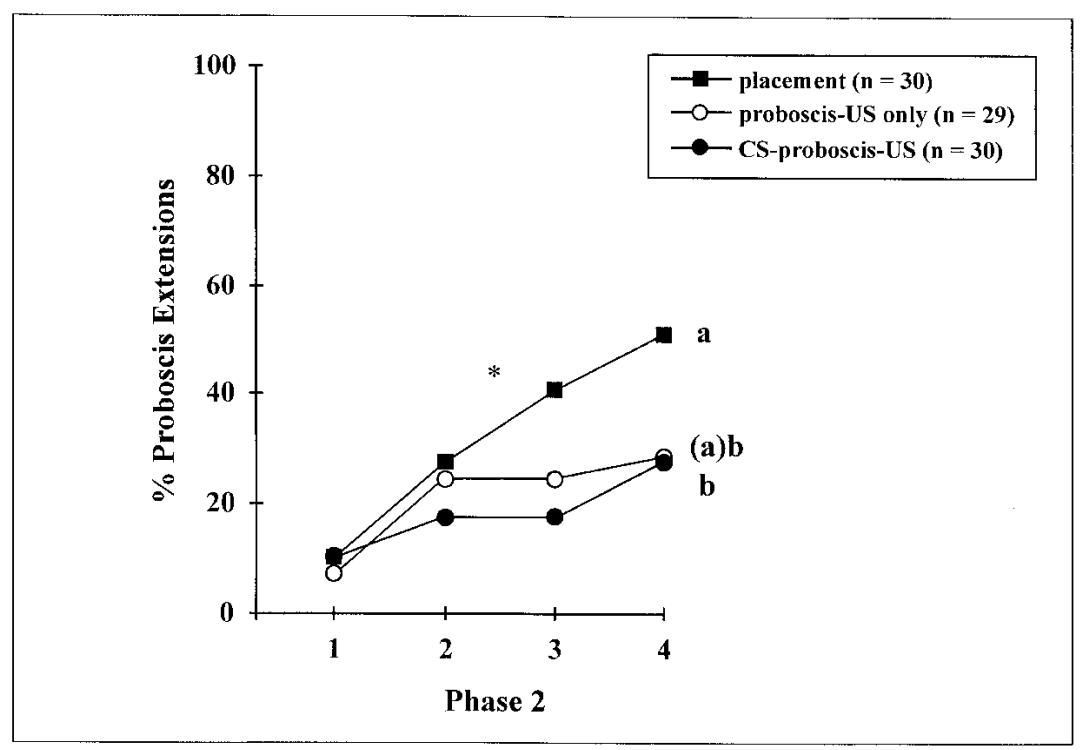

Figure 3 Bees' performances in the second phase of a conditioning procedure with a proboscis-US. In the first phase, bees received either placement trials, US-only trials, or CS-US associations. In the second phase, all bees received CS-US associations. Whereas bees receiving placement trials learned efficiently in the second phase, both groups of bees receiving either proboscis-US, or CS-proboscis-US associations showed reduced acquisition. This supports the argument for a nonassociative dependency of the proboscis-US effect found in Experiment 2. $\left(^{*}\right) P<0.05$, log-linear analysis. Different letters indicate significantly different response levels (pairwise log-linear analyses).

the compound-US used in other studies. Nonassociative effects (like sensitization) alone cannot explain the differentiation performance of bees conditioned with an antenna-US. Furthermore, the results of the control group prove that our experimental setup guarantees side-specific odor stimulation.

\section{Experiment 5: Side-Specificity of Antenna-US Input}

In this experiment we aimed to understand the properties of the antenna-US; in particular, we asked whether the reinforcing effect of an antenna-US (found in Experiment 4) is limited to one brain side, like sensitization (Experiment 1 ), or if contralateral reinforcement occurs.

\section{Protocol}

The experiment consisted of two acquisition phases of four conditioning trials each (9-min intertrial intervals). The CS was directed to one antenna during Phase 1 , and to the opposite antenna during Phase 2. Three groups of bees were trained according to the input side of the antenna-US: the US was thus given (1) ipsilaterally to the CS ("US same side"), (2) contralaterally to the CS ("US opposite side"), or (3) bilaterally ("US both sides"). Note that the protocol applied in group 1 was the same as in the antenna-US group of Experiment 2, and that in group 2, the US was on a different side with respect to the CS both in Phase 1 and in Phase 2.

\section{Results}

The performances of bees trained in an absolute conditioning procedure with different antenna-USs is presented in Figure 5. In the first phase, bees from all three groups showed low acquisition of conditioned responses to the unilateral CS, from $0 \%-3 \%$ at the first trial to $15 \%-$ $25 \%$ at the fourth trial. No significant difference appeared among groups in this phase (log-linear analysis, partial and marginal association $\chi^{2}<0.85$, NS, $2 \mathrm{df}$ ). In Phase 2, when the CS (and US) has changed sides, responses differed between groups: whereas bees from the "US same side" group showed a strong increase of conditioned responses (9\%$41 \%$ ), performances of the "US both sides" and of the "US opposite side" groups changed little (remaining below $22 \%)$. This difference is significant (loglinear analysis, partial and marginal association $\left.\chi^{2}>8.6, P<0.013,2 \mathrm{df}\right)$. Twoby-two comparisons show that the same side group responded significantly more than any of the other groups (partial and marginal association $\chi^{2}>4.3$, $P<0.035,1 \mathrm{df}$ ). Bees could be conditioned with all kinds of antenna-USs (although with relatively low performance: cf. the antenna-US group of Experiment 1), and when the side of CS input changed, only the group receiving CS and US on the same side learned efficiently.

\section{Experiment 6: CS-Specificity of Opposite Antenna-US}

Because some conditioning performance was observed for all three kinds of antenna-USs in Experiment 5, this experiment was designed to test if such performance actually has an associative basis, that is, is it caused by CS-US associations? As before (Experiment 4), we applied a differential conditioning experiment, in which we checked whether animals significantly differentiate $\mathrm{CS}+$ and $\mathrm{CS}-$, that is, whether they establish an associative memory trace with the antenna-US.

\section{Protocol}

All bees were subjected to a differential conditioning procedure, with one-sided CS+ and CS-, the US being provided either (1) ipsilaterally to the CSs ("US same side"), (2) contralaterally to them ("US opposite side"), or (3) bilaterally ("US both sides"). In all three groups, the conditioning procedure consisted of six CS+ trials and six CS- trials with intertrial intervals of $9 \mathrm{~min}$. On $\mathrm{CS}+$ trials, bees received the

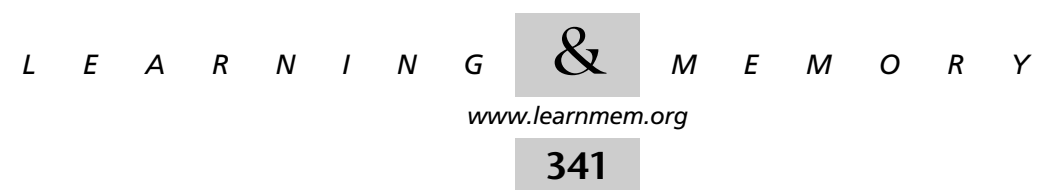




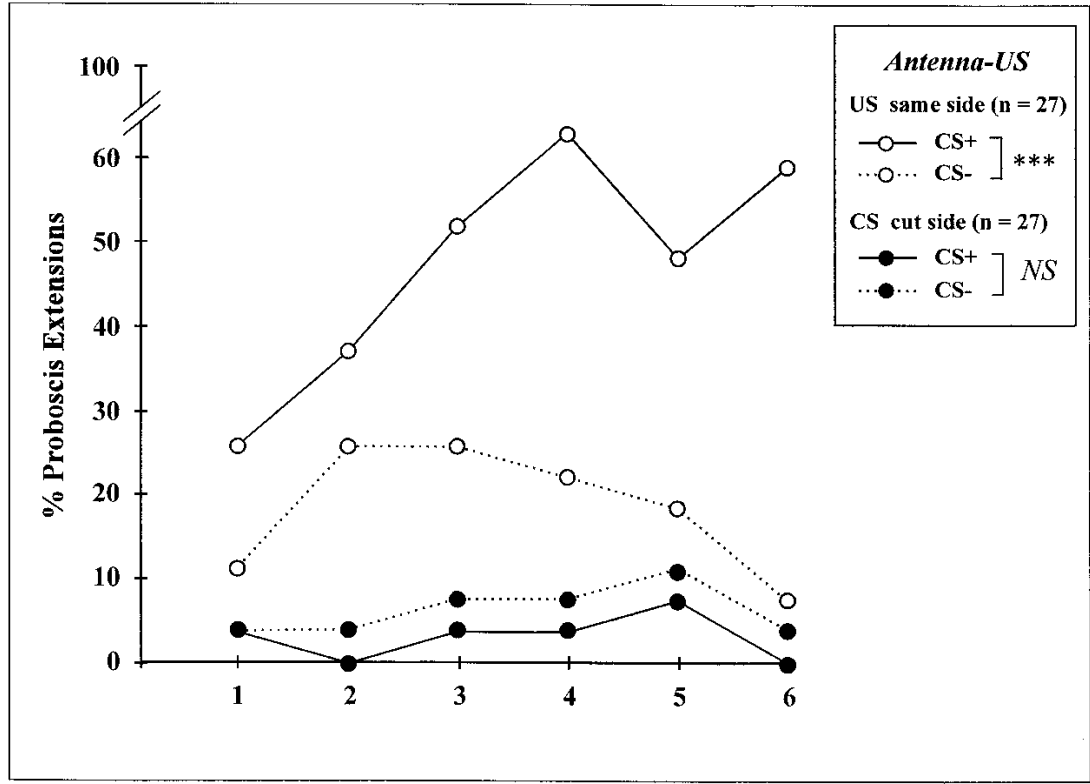

Figure 4 Performances of bees with a cut antenna in a differential conditioning procedure with unilateral CS+ and CS- and an antenna-US on the same side ("US same side"). As a control, another group of bees received the CS on the side without an antenna ("CS cut side"). Whereas the "US same side" group learned to differentiate CS+ and CS- with an antenna-US, no amount of differentiation was observed in the "CS cut side" group. (NS) Nonsignificant; $\left({ }^{* * *}\right) P<0.001, \log$-linear analysis.

CS+ in association with an antenna-US, and on CS- trials, they were stimulated with the CS- odor alone. The procedure began with a CS- trial, and CS+ (+) and CS- $(-)$ were pseudorandomized in a -++-+--+ order.

\section{Results}

The performances of bees trained in a differential conditioning procedure with different antenna-USs are presented in Figure 6. Bees trained with the US on the same side as the CS, or with the US on both sides showed fast learning. Responses to the CS+ increased from $6 \%$ at the first trial to $50 \%-58 \%$ at the end of training, whereas responses to the CS- decreased to $<3 \%$. In the group receiving the US contralaterally to the CS, acquisition was slower, starting after the fourth CS-US association (recorded at the fifth) trial, and reaching $34 \%$ at the end of training. The log-linear analysis shows a significant difference among groups (log-linear analysis, partial and marginal associations $\chi^{2}>24.7$, $P<0.001,2 \mathrm{df}$ ). In each group, responses to the CS+ were significantly higher than responses to the CS- (US same side" and "US both sides": partial and marginal association $\chi^{2}>41.2, P \ll 0.001,1 \mathrm{df} ;$ "US opposite side": partial and marginal association $\chi^{2}>14.2, P<0.001,1 \mathrm{df}$ ). Responses to the CS+ are significantly different among groups (partial and marginal associations $\chi^{2}>24.6, P<0.001,2 \mathrm{df}$ ), and two-by-two comparisons show that the "US opposite side" group responded significantly less than each of the other groups (partial and marginal associations $\chi^{2}>22.4$,
$P<0.001,1 \mathrm{df})$, with no difference between them (partial and marginal associations $\chi^{2}<2.1$, NS, $1 \mathrm{df}$ ). Bees thus established CS-specific memories with all types of antenna-USs, although learning took place more slowly with contralateral CS and US.

\section{DISCUSSION}

The present study indicates that (1) An antenna-US produces unilateral sensitization, whereas proboscis-USs and compound-USs produce bilateral sensitization. (2) All three types of US support similar acquisition with a unilateral CS. However, after rewarding with a proboscis-US, new learning appears to be blocked on the opposite side. (3) This proboscis-US effect also appears after US-only trials, which indicates a nonassociative basis. (4) Conditioning with an antenna-US leads to an associative memory trace, because bees perform well in a differential conditioning procedure. (5) Bees also show acquisition when a unilateral CS and the antenna-US are presented on opposite input sides. (6) Such performances also rely on an associative process, indicating that the antenna-US supports both a unilateral and a bilateral reinforcing function.

\section{Nonassociative US Processes}

In Experiment 1, we show that an antenna-US produces side-specific sensitization. In contrast, a US stimulation to the proboscis produces bilateral sensitization. A compound-US presentation (antenna and then proboscis) shows a tendency for more sensitization on the side that received the antennal part of the US, although this difference was not significant. This indicates that the compoundUS induces two processes, a unilateral antenna-US process, and a bilateral proboscis-US process. The fact that sensitization after an antenna-US is lateralized is particularly interesting, because another nonassociative learning phenomenon, habituation, was already found to be limited to the stimulated side (Braun and Bicker 1992). After habituation, however, a strong stimulation on the opposite side dishabituates the reflex, indicating some cross-talk of US pathways between brain sides with respect to nonassociative plasticity. As we discuss below, our data provide further evidence of bilateral antenna-US processes.

\section{Associative US Processes}

In an associative conditioning procedure, all three kinds of US (antenna-US, proboscis-US, and compound-US) in-

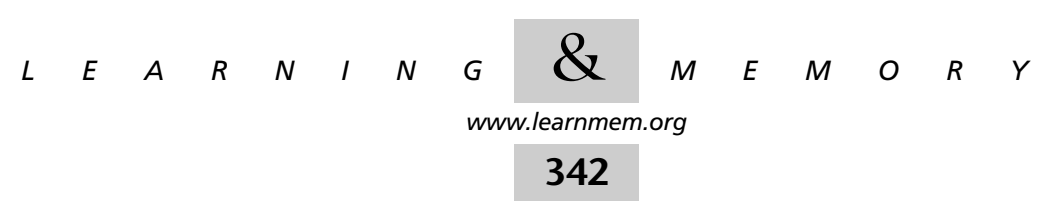




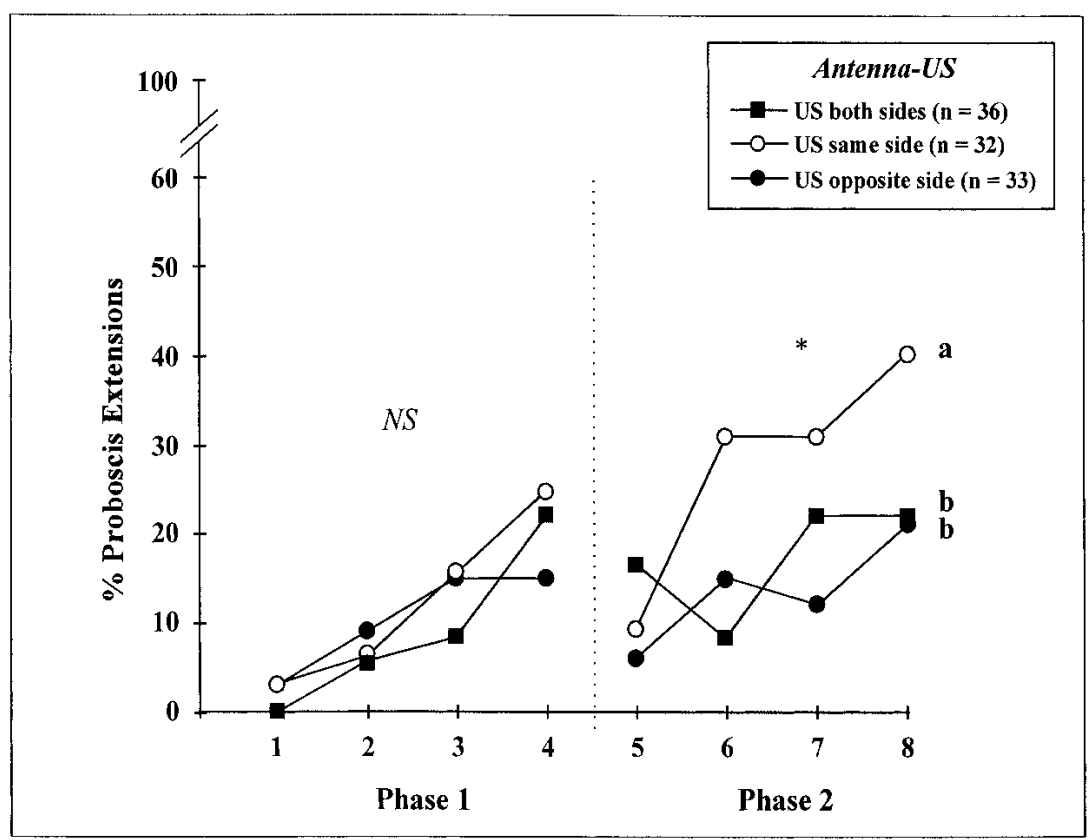

Figure 5 Performances of bees in a conditioning procedure with a unilateral $\mathrm{CS}$, and an antenna-US on the same side as the CS, on the opposite side, or on both sides. In the first phase, all groups showed limited performances. In the second phase, after the CS had changed sides, bees receiving the US ipsilaterally to the CS showed better acquisition than the two other groups. (NS) Nonsignificant; $\left(^{*}\right) P<0.05$, log-linear analysis. Different letters indicate significantly different response levels (pairwise log-linear analyses).

duced an increase in responses to the CS with repeated forward-pairing trials (Experiment 2; see also Bitterman et al. 1983). We know from extensive previous work that the memory trace produced by a compound-US is associative in nature, that is, responses to the CS are caused by the learning of the CS-US association, and not to nonassociative effects like sensitization (Bitterman et al. 1983; Menzel et al. 1993). Critical for such a conclusion are experiments like pseudoconditioning (where US and CS are presented explicitly unpaired) or differential conditioning (where a CS+ is associated to the US, and a CS- is not). In the latter case, associative learning can be inferred when animals significantly differentiate the two CSs. The fact that the antennaUS is equally capable of inducing such associative phenomena (Experiment 4) may appear contraintuitive because bees do not get any real appetitive reinforcement (meaning energy as food uptake) in an antenna-US. However, gustatory (sucrose) receptors are present at the level of the antennae (Sensilla chaetica, see below). Therefore, sucrose stimulation, rather than food uptake, activates the reward pathway in the bee brain, and both sites of sucrose stimulation (antennae, proboscis) appear to activate the reward system. We subjected bees to conditioning procedures with an antenna-US either ipsilateral to the CS, contralateral to it, or bilateral. A performance increase was observed in all cases, which was also shown to be associative, because bees conditioned with all three antenna-US types re- sponded specifically to the CS+ (Experiment 6). This suggests that, in addition to side-specific nonassociative learning (habituation and sensitization, see above), an antenna-US can also act as a reinforcer on the opposite brain side. Contralateral reinforcement appears to be weaker than ipsilateral reinforcement because slower acquisition was observed for contralateral CSs and USs in Experiment 6 , and more effective acquisition was found for ipsilateral reinforcement in the second phase of Experiment 5.

\section{Proboscis-US Effect}

Although bees learn an olfactory CS-US association with any US component (Experiment 2, Phase 1), switching the CS to the opposite side (Phase 2) showed a resistance to acquisition after reinforcement with a proboscis-US. To evaluate whether this was caused by an effect of the CS-US association on the contralateral side, or to the proboscis-US stimulation alone, we repeated this experiment and compared the bees' performances to those of animals receiving placement trials (control) or US-proboscis-only trials (Experiment 3). We found that the retardation of acquisition in the second phase was actually due to US processes, because the proboscis-US-only group showed the same reduced performances as the CS-US group. The proboscis-US effect is reminiscent of the US-preexposure effect that was shown in bees in an aversive conditioning task (Abramson and Bitterman 1986) and suggested for PER conditioning (Bitterman et al. 1983). During US preexposure, an animal is repeatedly stimulated with the US alone and may form an association between context stimuli and the US, which would in turn induce resistance to CS-US acquisition. Based on the morphology of the identified reward pathway in bees (the $\mathrm{VUM}_{\mathrm{mx} 1}$, see below), we believe that the reinforcement produced by proboscis-US stimulations is a bilateral process. Therefore, in the first phase of Experiment 2, bees received a $\mathrm{CS}$ on one brain side associated with the proboscis-US and simultaneously no CS on the other side, associated with the proboscis-US. This could have produced a CS-US association on one side and a context-US association (including no CS) on the other. When the CS was then switched to this side, this might lead to a typical US-preexposure effect, retarding the CS-US acquisition. Interestingly, the same effect was found for the antenna-US. In Experiment 5, after changing the CS side (Phase 2), acquisition was much higher for bees receiving CS and US on the same side than for bees receiving the US on the opposite

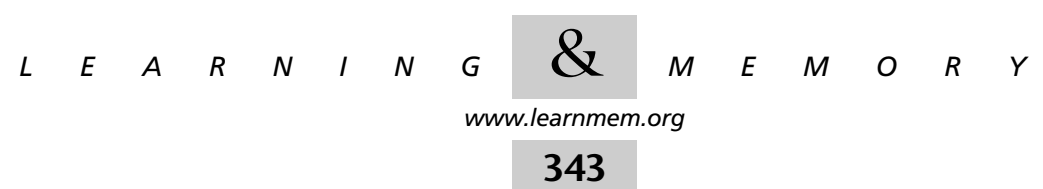




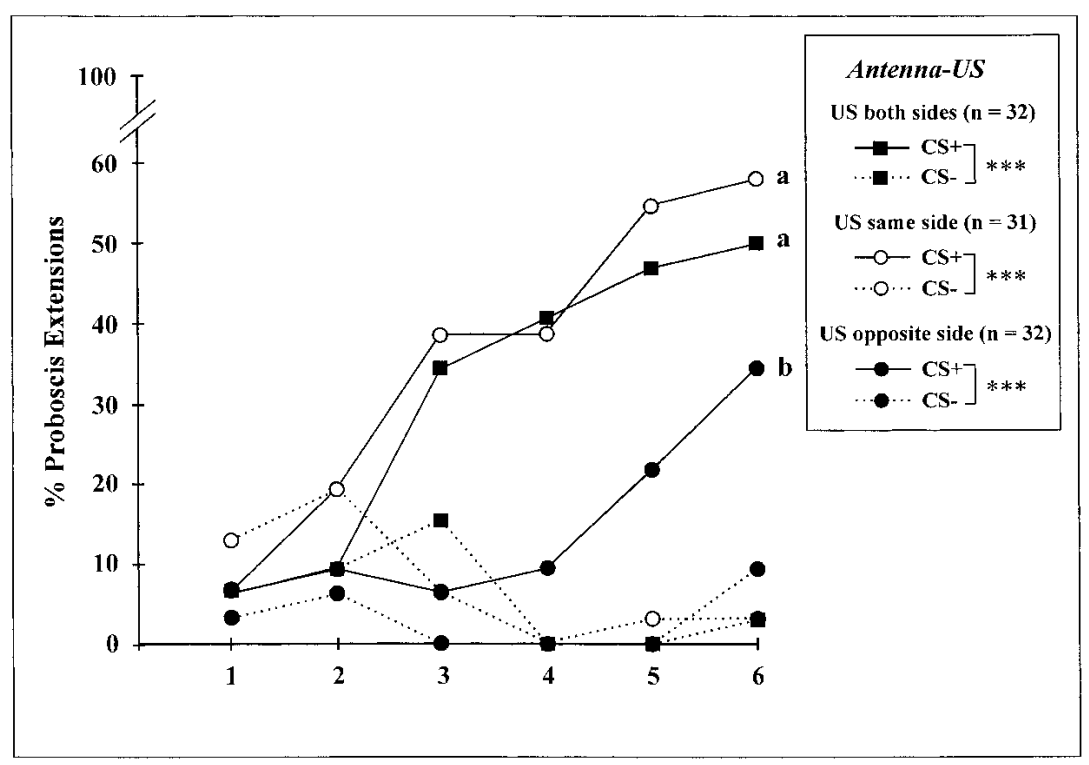

Figure 6 Bees' performances in a differential conditioning procedure with a unilateral CS and different types of antenna-US: on the same side as the CS, on the opposite side, or on both sides. All groups of bees learned to significantly differentiate the CS+ and the CS-. (***) $P<0.001 ; \log$-linear analysis. However, when the antenna-US was provided contralaterally to the CSs, learning took place more slowly. Different letters indicate significantly different levels of response to the CS+ (pairwise log-linear analyses). No difference appeared among responses to the CS-.

side or on both sides. When conditioning bees with the US on the side opposite to the CS, two associations are probably built at the same time. On the CS side, a CS-US association that takes time to develop (see Experiment 6) and relies on bilateral processes is built. On the other side, where no CS was given, a context-US association (including no CS) could develop, which would, as postulated for the US-proboscis, retard later acquisition of the CS-US association on this side. A logical consequence of this hypothesis is that when bees receive a bilateral antenna-US, the same effect should appear. The reduced acquisition of the bothsides group in the second phase of Experiment 5 confirms this view.

\section{Properties of the Compound-US}

An intriguing result was observed in Experiment 2. Although a proboscis-US induced US-preexposure effects when the CS was switched to the opposite side, this did not occur with a compound-US. This indicates that the compound-US provides more (and other) reward information than just the addition of antenna-US and proboscis-US stimulations. From a biological point of view, one might argue that the antenna-US has a signaling function for the reinforcement, whereas the proboscis-US assesses the overall quality of the reinforcement. Indeed, previous work showed that when applying a compound stimulation in a tactile learning paradigm, the quality of the proboscis-US but not of the antenna-US is crucial in determining the level of acquisition of the CS-US association (Scheiner 2001; R. Scheiner, pers. comm.). For instance, conditioning with a compound-US consisting of fixed proboscis-US (30\% sucrose solution) but of various antenna-USs (water, $1.6 \%$ and $30 \%$ sucrose solutions, and even a salt solution), led to good conditioning performance in all cases. In contrast, when a $30 \%$ sucrose solution was proposed to the antenna, bees learned only when the sucrose concentration given to the proboscis confirmed what was given to the antenna: when given a low sucrose concentration (1.6\%), water or a salt solution to the proboscis led to very low acquisition. According to these data and ours, the antenna detects the presence of water and sucrose, which triggers, depending on the motivational state of the bee (and its response threshold; Scheiner et al. 1999), the extension of the proboscis, and builds a first CS-US association. Additionally, information about US quality, gathered at the proboscis, could serve to modify the strength of this association during the consolidation process, or alternately to create an additional CS-US association. Further work should attempt to elucidate this question.

\section{Bilateral Transfer}

In two experiments (Experiments 2 and 5), bees were subjected to two conditioning phases, the side of CS input changing from one phase to the other. After this change of CS input, a drop in responses was observed, indicating that the CS-US association was not yet retrievable on the other brain side. This was the case for all US components: compound-US, antenna-US, and proboscis-US. This result complements those from a previous study, where we found that a CS-US association built on one side could be retrieved on the contralateral side (Sandoz and Menzel 2001). Interestingly, the main difference between the two studies resides in the amount of time after which transfer was tested. In the present experiments, transfer was tested in Phase 2 after a 9-min intertrial interval, whereas in the previous study, tests for bilateral transfer were carried out $3 \mathrm{~h}$ and 24 $\mathrm{h}$ after conditioning. Indeed, we think that time is a critical factor for the occurrence of bilateral transfer, as we found recently that retrieval on the contralateral side increases from $10 \mathrm{~min}$ to $3 \mathrm{~h}$ after conditioning (J.C. Sandoz and R. Menzel, in prep.). This indicates that the first phases of the odor CS-US association are unilateral, but later phases are bilaterally accessible.

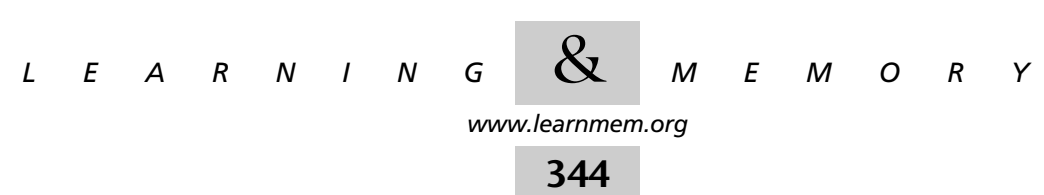




\section{Neural Substrates of the US}

The neural substrates of both the CS and the US pathway in PER conditioning are rather well-known (Menzel 2001). A key finding was the discovery of a single neuron, the $\mathrm{VUM}_{\mathrm{mx} 1}$ (ventral unpaired median neuron of the maxillary neuromere 1 ), which converges bilaterally with the CS pathway, at the level of the antennal lobes, the mushroom bodies, and the lateral protocerebral lobes (Hammer 1993). This neuron was shown to mediate the reinforcement in PER conditioning, because the forward (but not backward) pairing of an odor CS with an artificial depolarization of $\mathrm{VUM}_{\mathrm{mx} 1}$ produces an associative memory trace. Because $\mathrm{VUM}_{\mathrm{mx} 1}$ responds both to sucrose stimulations to the antenna and to the proboscis, sucrose receptors on both the antennae and on the proboscis must connect to $\mathrm{VUM}_{\mathrm{mx} \mathbf{1}}$. However, the exact projection patterns of gustatory receptors are as yet poorly understood. On the antenna, sensilla trichodea type D (i.e., sensilla chaetica; Dostal 1958; Galić 1971) are thought to be involved in gustatory perception (Martin and Lindauer 1966; Esslen and Kaissling 1976; Whitehead and Larsen 1976a,b). Two possibilities concerning their projections have been suggested: most of the sensory neurons of the antenna lead directly to the antennal lobe (antennal tracts T1-T4, mostly olfactory; Pareto 1972; Suzuki 1975; Mobbs 1982), but a considerable portion of

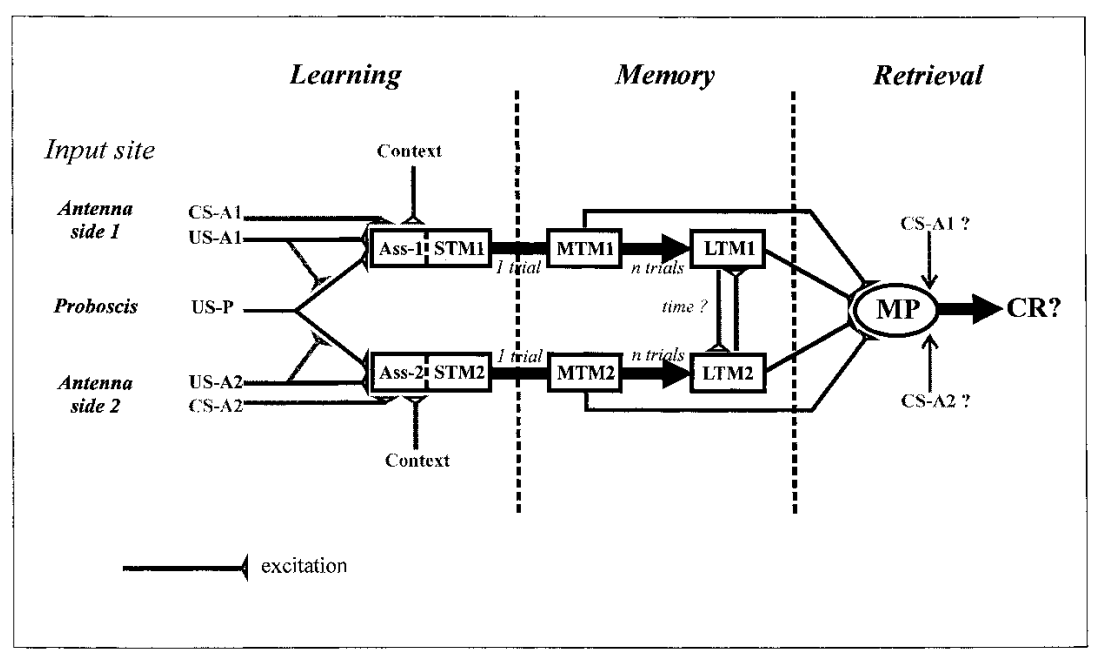

Figure 7 Functional model of the side-specificity of olfactory learning in the honeybee. CS and US stimulations are represented according to the input site: CS-A1 and US-A1 refer to stimulations to the antenna of side 1, and CS-A2 and US-A2 to stimulations to the antenna of side 2. US-P corresponds to the proboscis-US component. On each side, CS and US processes project to an association center (Ass-1 and Ass-2), where the associative pairing effects take place. CS-US associations as well as context-US associations are built, according to the salience (presence or absence) of a CS on this side. The content of this association as well as transient sensitization effects control unilateral Short-Term Memory phases (STM1 and STM2). Through time and/or additional training, memories are consolidated into Mid-Term Memory (MTM1 and MTM2) and Long-Term Memory phases (LTM1 and LTM2). LTM phases are characterized by the use of both brain sides and bilateral transfer effects (Sandoz and Menzel 2001). When tested with the CS on one side, the retrieval process starts, and information stored in the memory stores of this side is used to control the animal's responses (MP) Proboscis motor program; (CR) conditioned response. the sensory neurons bypass the antennal lobe altogether, and project to the dorsal lobe (tract $\mathrm{T} 5$ ), to the caudal part protocerebrum (tract $\mathrm{TC}_{\mathrm{I}}$ ), and to the suboesophaII tially be directed to either (or both) the antennal lobe and the SOG. Side-specific nonassociative processes like habituation and sensitization, as well as side-specific associative processes (antenna-US), could take place at the level of the antennal lobe, under direct influence of projections from the gustatory receptors of the antenna. Cnts 5 and 6) is probably assured by a projection of antake place, albeit with a different time course, as seen in Experiment 6. At the level of the mouthparts, gustatory receptors (sensilla chaetica; Whitehead and Larsen 1976a) are placed on the glossa, galeae, and labial palps, but also in e hypopharynx and epipharynx (Galić 1971; Whitehead and (Satzinger 1980 Gaide 1983). It is reasonable to think that they synapse there either directly, or via local interneurons, onto the $\mathrm{VUM}_{\mathrm{mx} 1}$ neuron, thus inducing bilateral reinforcement. However, the connections of antennal and proboscis gustatory receptors with reinforcing circuits (probably the $\mathrm{VUM}_{\mathrm{mx} 1}$ neuron) we propose are still hypothetical, and particular effort should be invested in anatomical studies that would help to determine precisely the neural processes of the US pathway.

\section{Functional Model of Side-Specific Processes}

Based on our results and on our knowledge and predictions concerning the CS and US pathways, we developed a model summarizing side-specific and bilateral processes in olfactory PER conditioning (Fig. 7). This model consists of three functional subcompartments, related to Learning, Memory, and Retrieval, respectively. In the Learning phase, the animal receives a set of stimulations with a CS and/or a US, on one or both sides. Each side of the brain houses primary association centers where the CS/US coincidence is detected and associations are built. These associations, held in ShortTerm Memory (STM) storage, lead through a time-, and event-dependent process to

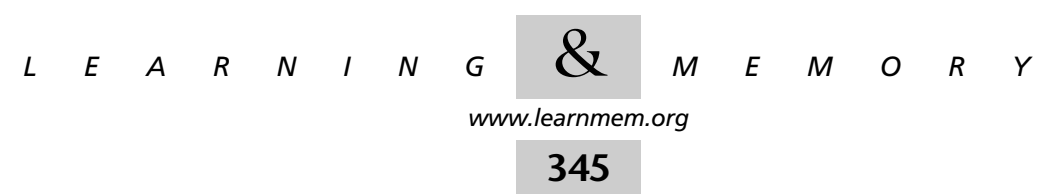


different forms of Memory-Mid-Term Memory (MTM) and Long-Term Memory (LTM) phases. When a learned CS is presented to the bee on either side, the Retrieval process starts, and the stored information about the learned CS is retrieved from this side. This process controls the behavior of bees via the proboscis extension motor program. As shown by anatomical studies (Pareto 1972; Mobbs 1982), the CS input is unilateral on each side, olfactory receptor neurons on the antenna projecting to the glomeruli of the antennal lobe on the ipsilateral side only, thus providing the bee with unilateral odor information on each side (CS-A1). The antenna-US, in parallel to triggering the extension of the proboscis (data not shown), induces first a unilateral reinforcing process. Coincidence detection in the association center on this side (Ass-1) builds a unilateral memory trace (STM1), which has a strong nonassociative component (is highly dependent on sensitization; Menzel 1990, 1999). CS-specific memory consolidates through time and other conditioning trials into associative unilateral MTM1 and LTM1. As was found in previous work (Sandoz and Menzel 2001), the learned association is retrievable from the opposite side after some time (3-24 h). Therefore, some of the content of LTM is transferred from side to side. As found in the present study, the proboscis-US induces bilateral reinforcing processes (conveyed by the $\mathrm{VUM}_{\mathrm{mx} 1}$ neuron), which build unilateral or bilateral memories, depending on the unilateral or bilateral presentation of the CS. Importantly, when the CS is provided on only one side, a olfactory memory is formed on this side, but on the opposite side, a context-US association (including no CS) is formed, which retards the formation of a subsequent CS-US association on this side (USpreexposure effect, Experiments 2 and 6). In parallel to its unilateral reinforcing function, the antenna-US induces bilateral reinforcement (through activation of $\mathrm{VUM}_{\mathrm{mx} 1}$ ), because contralateral presentation of CS and US (CS-A1 and US-A2 or CS-A2 and US-A1; Experiments 5 and 6) also leads to significant learning. In this case, a context-US association is built on the US side, which will retard acquisition if the CS is switched to this side (Experiment 5). Lastly, the side itself (as a context stimulus) can also, in association with the presented CS, enter into association with the US. As was found in a previous study (Sandoz and Menzel 2001), bees can learn a discrimination task of the type $\mathrm{A}+\mathrm{B}-/ \mathrm{B}+\mathrm{A}-$, where each of the two odors is rewarded on one side, but not on the opposite side. In this case, bees would rely on higher-order cognitive capacities, learning a kind of configuration between an odor and the side on which it was rewarded. During retrieval, the side would thus play a crucial role in retrieving either an excitatory memory on one side or an inhibitory memory on the other side.

\section{Conclusion}

Our work has addressed the side-specificity of the US pathway, by conditioning bees with unilateral and bilateral an-
tenna-US, with proboscis-US, and with compound-US. This and a previous study (Sandoz and Menzel 2001) have allowed us to build a model of side-specific olfactory conditioning in the honeybee. Although both the CS and the US pathways are relatively well known in the bee, our model is highly speculative with respect to the neural substrates involved. Nevertheless, based on the few anatomical studies carried out so far, as well as on our behavioral results, we can make a number of predictions concerning US processes that should be tested in the future. In particular, special attention should be paid to elucidating the projections of sucrose gustatory receptors (antenna, proboscis, and tarsae of the front legs) in the brain of the bee, as well as their convergence with the $\mathrm{VUM}_{\mathrm{mx} 1}$ neuron.

\section{MATERIALS AND METHODS}

\section{Honeybees}

Worker bees were collected from an indoor flight room with constant temperature and humidity conditions $\left(24^{\circ} \mathrm{C}, 60 \%\right.$ relative humidity). They were immobilized by brief cooling and fixed in metal harnesses with tape. The head capsule of each bee was fixed to the tape with a drop of low-temperature melting wax to prevent movement. In Experiments 1-3, the bees were fed to satiation with a $40 \%$ sucrose solution and kept overnight. Conditioning experiments were performed the next morning. In Experiments 4-6, the bees were kept for $2 \mathrm{~h}$ before the experiments began.

\section{Stimulation Apparatus}

The olfactory space of bees was delimited using two different methods, depending on the type of experiment. In Experiments 1-3, a removable wall device was used. To allow control over the individual components of the US, the device consisted of a removable vertical wall, which could be placed between the antennae of each bee before each trial. The separation wall was made of Plexiglas ( 1 $\mathrm{mm}$ thick) and had a small perforation at the level of the proboscis to make it easily accessible from both sides. This allowed us to give a sucrose stimulation to the proboscis from either side of the apparatus. Odor presentations were precisely directed to each antenna using glass pipettes. Two pipettes, one on each side of the wall, were fixed in front of the bee, with their outlet placed at a distance of $1 \mathrm{~cm}$ from the antenna. Each pipette could be connected to a 20-mL syringe containing the odor source. During onesided odor stimulations, an odor syringe was activated, and a thin odor flow was given to one antenna. An exhaust placed $10 \mathrm{~cm}$ behind the bee ensured that the flows on each side of the wall were laminar and that all released odors were extracted from the experimental room. Bees were placed into the apparatus one at a time, the wall was installed between the antennae, and each pipette was precisely directed to one antenna. The bee was left for $2 \mathrm{~min}$ to adapt to the experimental conditions. In Experiments 4-6, a new device was developed that allowed applying side-specific odor stimulations under computer control (it was necessary when more than one odor was used, as in Experiments 4 and 6). As in a previous study (Sandoz and Menzel 2001), each individual bee had a thin plastic wall on its head, which separated the two sides of its olfactory space. These walls were secured on the head and waxed in place in such a way that all remaining spaces were closed and the proboscis was placed on one side (left side for half the bees, right side for the other half). Therefore, although only the bee's anten-

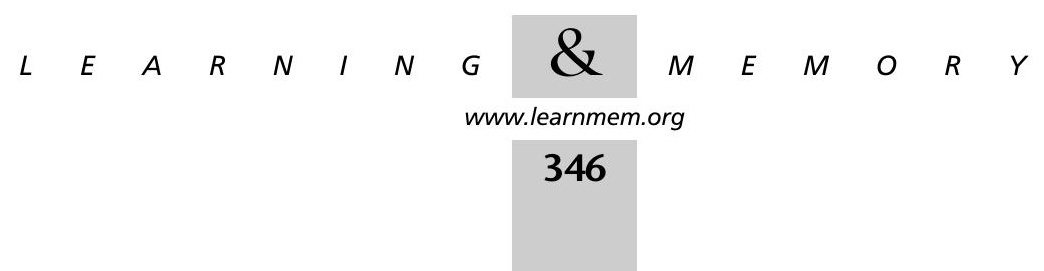


nae received a US in the experiments, the proboscis could move freely. During conditioning, each bee was placed individually in front of the bilateral odor-supplying device. Identical airstreams were provided on the two sides, and were directed to each antenna (on each side of the plastic wall) via Teflon tubing $(5 \mathrm{~mm}$ diameter, $5 \mathrm{~cm}$ length). Before reaching the bee, each air stream was directed through one of three channels, regulated by three valves controlled by the experimenter via a computer. Each channel contained a cartridge made from the cut end of a 1-mL syringe. The first channel, where the air stream flowed continuously when no odor stimulation was given, contained a cartridge holding a piece of filter paper. The second and third channels each contained an odor source, that is, a piece of filter paper soaked with odor substance. Behind the head of the bee, an exhaust removed the released odorants from the experimental room.

\section{Stimuli}

Clove oil (from a local pharmacy, Berlin-Dahlem, Germany) was used as the CS throughout, because it provides intermediate performance levels, which allow the researcher to carry out a greater number of conditioning trials. In two experiments where differential conditioning procedures were performed (Experiments 4 and 6), orange flower oil (local pharmacy, Berlin-Dahlem, Germany) was used as the second odor. The odor source was a $1-\mathrm{cm}^{2}$ piece of filter paper soaked with $5 \mu \mathrm{L}$ of pure substance, which was inserted into either a 20-mL syringe (Experiments $1-3$ ) or into an empty cartridge (Experiments 4-6). A 40\% (w/w) sucrose solution was used as the US.

\section{Stimulations}

\section{Rewarded (CS-US or CS+) Trials}

The CS odor was presented to the bee for $4 \mathrm{sec}$ on one side. Then, 3 sec after onset of the CS, US stimulation began. Three possible USs could be given:

1. Antenna-US. The US was given to only one antenna by briefly touching it with the sucrose solution (until a PER appeared).

2. Proboscis-US. The US was given directly to the proboscis. The bee could lick sucrose solution for $3 \mathrm{sec}$.

3. Compound-US. The US was first given to one antenna, thereby eliciting the proboscis extension reflex, then to the proboscis. The bee could then lick sucrose solution for $3 \mathrm{sec}$.

For antenna-US and compound-US, the antennal US could be given either on the same side as the CS (referred to as "ipsilateral to the CS") or on the other side ("contralateral to the CS").

\section{Sensitizing (US-Only) Trials}

The US was given without any CS stimulation. As above, three possible USs could be given (antenna-US, proboscis-US, or compound-US).

\section{Unrewarded (CS-) Trials}

The CS- was presented on one side, without any US stimulation.

\section{Statistics}

In Experiment 1, differences in the percentages of animals responding to the odor stimuli between the ipsilateral and contralateral sides were evaluated in each group by a $G$-test with $1 \mathrm{df}$. In Experiments 2-6, comparisons among groups of performances were made using a log-linear analysis of the frequencies of bees responding at each trial. Interactions of the design variables (conditioning trials, treatment, and/or CS+ vs. CS-) with the development of odor-evoked PER were considered significant only if both partial and marginal association $\chi^{2}$ s were significant $(P<0.05)$. When significant, two-by-two comparisons were made between groups with log-linear analyses, and were considered significant under the same conditions as mentioned above.

\section{ACKNOWLEDGMENTS}

We are grateful to M. Wurm for her editorial help. J.C. Sandoz was funded by a research fellowship from the Alexander von Humboldt Foundation. The research of R. Menzel is supported by the Deutsche Forschungsgemeinschaft.

The publication costs of this article were defrayed in part by payment of page charges. This article must therefore be hereby marked "advertisement" in accordance with 18 USC section 1734 solely to indicate this fact.

\section{REFERENCES}

Abramson, C.I. and Bitterman, M.E. 1986. The US-preexposure effect in honeybees. Anim. Learn. Behav. 14: 374-379.

Bitterman, M.E., Menzel, R., Fietz, A., and Schäfer, S. 1983. Classical conditioning of proboscis extension in honeybees. J. Comp. Psychol. 97: 107-119.

Braun, G. and Bicker, G. 1992. Habituation of an appetitive reflex in the honeybee. J. Neurophysiol. 67: 588-598.

Dostal, B. 1958. Riechfähigkeit und Zahl der Riechsinneselemente bei der Honigbiene. Z. vergl. Physiol. 41: 179-203.

Erber, J., Masuhr, T., and Menzel, R. 1980. Localization of short-term memory in the brain of the bee, Apis mellifera. Physiol. Entomol. 5: 343-358.

Esslen, J. and Kaissling, K. E. 1976. Zahl und Verteilung antennaler Sensillen bei der Honigbiene (Apis mellifera L.). Zoomorphology 83: $227-251$.

Gaide, M. 1983. "Die Projektionen des Labial- und Maxillennerven im Unterschlundganglion der Biene. Neuroanatomische Untersuchungen zum Rüsselreflex der Biene (Apis mellifica carnica).” Diplom thesis, Freie Universität Berlin, Germany.

Galić, M. 1971. Die Sinnesorgane an der Glossa, dem Epipharynx und dem Hypopharynx der Arbeiterin von Apis mellifica L. (Insecta, Hymenoptera). Z. Morphol. Tiere 70: 201-228.

Gerber, B. and Ullrich, J. 1999. No evidence for olfactory blocking in honeybee classical conditioning. J. Exp. Biol. 202: 1839-1854

Hammer, M. 1993. An identified neuron mediates the unconditioned stimulus in associative olfactory learning in honeybees. Nature 366: 59-63.

Hammer, M., Braun, G., and Mauelshagen, J. 1994. Food-induced arousal and nonassociative learning in honeybees: Dependence of sensitization on the application site and duration of food stimulation. Behav. Neural. Biol. 62: 210-223.

Horn, G. 1998. Visual imprinting and the neural mechanisms of recognition memory. Trends Neurosci. 21: 300-305.

Hosler, J.S. and Smith, B.H. 2000. Blocking and the detection of odor components in blends. J. Exp. Biol. 203: 2797-2806.

Martin, H. and Lindauer, M. 1966. Sinnesphysiologische Leistungen beim Wabenbau der Honigbiene. Z. vergl. Physiol. 53: 372-404.

Masuhr, T. and Menzel, R. 1972. Learning experiments on the use of side-specific information in the olfactory and visual system in the honey bee (Apis mellifica). In Information processing in the visual systems of arthropods (ed. R. Wehner), pp. 315-322. Springer, Berlin.

Menzel, R. 1990. Learning, memory and "cognition" in honey bees. In Neurobiology of comparative cognition (eds. R.P. Kesner and D.S. Olten), pp. 237-292. Erlbaum, Hillsdale, NJ.

. 1999. Memory dynamics in the honeybee. J. Comp. Physiol. A 185: $323-340$

. 2001. Searching for the memory trace in a mini-brain, the honeybee. Learn. Mem. 8: 53-62.

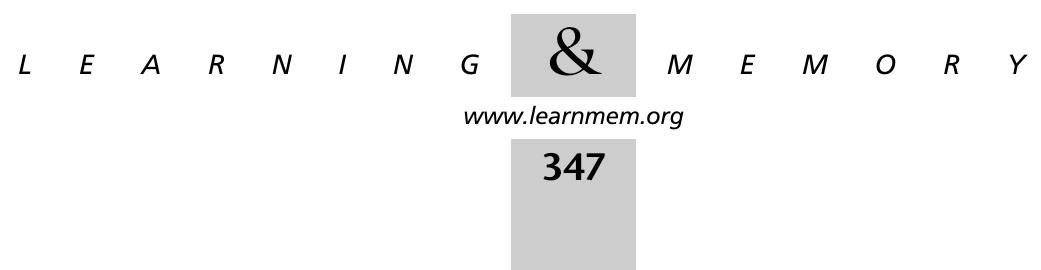


Menzel, R., Erber, J., and Masuhr, T. 1974. Learning and memory in the honeybee. In Experimental analysis of insect behaviour (ed. L.B. Browne), pp. 195-217. Springer, Berlin.

Menzel, R., Hammer, M., Braun, G., Mauelshagen, J., and Sugawa, M. 1991. Neurobiology of learning and memory in honeybees. In The behaviour and physiology of bees (eds. J.L. Goodman and R.C. Fischer), pp. 323-353. CAB International, Wallingford, UK.

Menzel, R., Greggers, U., and Hammer, M. 1993. Functional organization of appetitive learning and memory in a generalist pollinator, the honey bee. In Insect learning (ed. A.C. Lewis), pp. 79-125. Chapman Hall, New York.

Mobbs, P.G. 1982. The brain of the honeybee Apis mellifera. I. The connections and spatial organization of the mushroom bodies. Phil. Trans. R. Soc. Lond. B 298: 309-354.

Pareto, A. 1972. Die zentrale Verteilung der Fühlerafferenz bei Arbeiterinnen der Honigbiene, Apis mellifera L. Z. Zellforsch. 131: $109-140$

Rose, S.P.R. 2000. God's organism? The chick as a model system for memory studies. Learn. Mem. 7: 1-17.

Sandi, C., Patterson, T.A., and Rose, S.P.R. 1993. Visual input and lateralization of brain function in learning in the chick. Neuroscience 52: 393-401

Sandoz, J.C. and Menzel, R. 2001. Side-specificity of olfactory learning in the honeybee: Generalization between odors and sides. Learn. Mem. 8: 286-294.

Satzinger, H. 1980. "Neuroanatomische Untersuchungen zum Rüsselreflex der Honigbiene (Apis mellifera c.)." Doctoral thesis, Freie Universität Berlin, Germany.

Scheiner, R. 2001. "Sucrose responsiveness and behaviour in honey bees (Apis mellifera L.)." Doctoral thesis, Technische Universität Berlin, Germany.

Scheiner, R., Erber, J., and Page Jr., R.E. 1999. Tactile learning and the individual evaluation of the reward in honey bees (Apis mellifera $\mathrm{L}$.). J. Comp. Physiol. A 185: 1-10.

Springer, S.P. and Deutsch, G. 1981. Left brain right brain. W.H. Freeman, San Francisco.

Suzuki, H. 1975. Convergence of olfactory inputs from both antennae in the brain of the honeybee. J. Exp. Biol. 62: 11-26.

Thorn, R.S. and Smith, B.H. 1997. The olfactory memory of the honeybee Apis mellifera. III. Bilateral sensory input is necessary for induction and expression of olfactory blocking. J. Exp. Biol. 200: 2045-2055.

Vallortigara, G. 2000. Comparative neuropsychology of the dual brain: A stroll through animals' left and right perceptual worlds. Brain \& Lang. 73: 189-219.

Whitehead, A.T. and Larsen, J.R. 1976a. Electrophysiological responses of galeal contact chemoreceptors of Apis mellifera to selected sugars and electrolytes. J. Insect Physiol. 22: 1609-1616.

- $1976 \mathrm{~b}$. Ultrastructure of the contact chemoreceptors of Apis mellifera L. (Hymenoptera: Apidae). Intl. J. Insect Morphol. Embryol. 5: 301-315.

Received June 3, 2002; accepted in revised form August 13, 2002. 


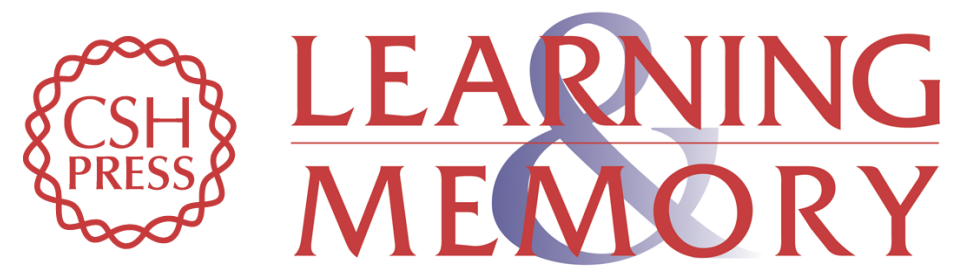

\section{Side-Specificity of Olfactory Learning in the Honeybee: US Input Side}

Jean-Christophe Sandoz, Martin Hammer and Randolf Menzel

Learn. Mem. 2002, 9:

Access the most recent version at doi:10.1101/lm.50502

References This article cites 23 articles, 7 of which can be accessed free at:

http://learnmem.cshlp.org/content/9/5/337.full.html\#ref-list-1

License

Email Alerting Receive free email alerts when new articles cite this article - sign up in the box at the Service top right corner of the article or click here. 